\title{
Allatostatin modulates skeletal muscle performance in crustaceans through pre- and postsynaptic effects
}

\author{
Sabine Kreissl, Torsten Weiss, Stefan Djokaj, Olga Balezina* and Werner Rathmayer \\ Department of Biology, University of Konstanz, D 78457 Konstanz, Germany
}

Keywords: Eriphia spinifrons, Idotea, inhibition, modulation, muscle contraction, neuromuscular transmission, neuropeptide

\begin{abstract}
Allatostatins, originally identified in insects as peptide inhibitors of juvenile hormone biosynthesis, are regarded as potent inhibitory regulators of intestinal muscles in insects and crustaceans. However, accumulating data indicate that allatostatins might also be involved in modulation of skeletal neuromuscular events. We show that most ganglia of two isopod crustaceans (Idotea baltica and $I$. emarginata) contain pairs of large, allatostatin-immunoreactive motor neurons which supply several segmental muscles. Among them are the dorsal extensor muscles, of which some fibres receive immunoreactive, varicose innervation. We demonstrate, on identified muscle fibres, that allatostatin exerts a twofold inhibitory effect: it reduces contractions of single voltage-clamped fibres, and it decreases the amplitude of evoked excitatory junctional currents recorded from individual release boutons. No change in excitationcontraction threshold or in passive membrane parameters was observed. As the amplitude of miniature currents generated by spontaneously released single transmitter quanta was not changed, the inhibitory effect of the peptide on junctional currents must be of presynaptic origin. Supportive results were obtained on leg muscles of the crab Eriphia spinifrons, where allatostatin decreased evoked synaptic currents by reducing the mean number of transmitter quanta released by presynaptic depolarization without affecting the amplitudes of currents generated by single quanta. This effect of allatostatin was similar for two functionally different neurons, the slow and the fast closer excitor.

The data show that allatostatin occurs in identified motor neurons of Idotea and exerts complementary pre- and postsynaptic modulatory effects which reduce muscle responses. Thus, allatostatin counteracts the effects of another neuropeptide, proctolin, which is also present in Idotea and causes potentiating effects on the same muscle fibres.
\end{abstract}

\section{Introduction}

A family of small neuropeptides characterized by the common $\mathrm{C}$ terminal pentapeptide sequence $\mathrm{YXFGL} \mathrm{NH}_{2}$ was originally isolated from the nervous system of the cockroach Diploptera punctata (Pratt etal., 1989, 1991; Woodhead etal., 1989, 1994). Because they inhibit juvenile hormone synthesis in the corpora allata, they were termed allatostatins. Using biochemical isolation techni ques, a large number of peptides sharing a homologous $\mathrm{C}$ terminus were subsequently identified in other insects including cockroaches (Yu etal., 1993; Bellés etal., 1994; Weaver etal., 1994), locusts (Veelaert etal., 1996), crickets (Lorenz etal., 1995), Lepidoptera (Duve etal., 1997a,b), and Diptera (Duve etal., 1993, 1994, 1995, 1996; Duve \& Thorpe, 1994; Veenstra etal., 1997). Immunocyto chemical studies revealed a widespread distribution of allatostatins. They occur in central and peripheral nervous systems, on antennal hearts and on visceral muscles of different insect species (for review see Stay etal., 1994; Nässel, 1996; Duve etal., 1997b; Gäde et al., 1997). Allatostatin genes have been cloned and sequenced in several insects (Donly et al., 1993; Reichwald et al., 1994; Ding et al., 1995; East etal., 1995; Vanden Broeck etal., 1996; Veenstra et al., 1997).

Correspondence: Professor Werner Rathmayer, Department of Biology, University of Konstanz, D 78457 Konstanz, Germany.

E mail: werner.rathmayer@uni konstanz.de

*Present address: Department of Human and Animal Physiology, Moscow State University, 119889 Moscow, GUS
The discovery of at least 50 different insect allatostatins (Duve etal., 1997a) and their wide distribution throughout the nervous system and in other tissues, particularly the intestine, suggest other functions in addition to regulation of juvenile hormone biosynthesis. Indeed, allatostatins were shown to control gut motility by inhibiting contractions of the fore and hindgut in insects (Lange et al., 1993, 1995; Vanden Broeck etal., 1996; Veelaert et al., 1996; Weiss \& Agricola, 1996; Duve etal., 1997b). The mechanisms underlying these physiological actions are unknown.

Recently, allatostatins were also reported in crustaceans (Abel etal., 1994; Skiebe \& Schneider, 1994; Christie etal., 1995; Duve etal., 1997c; Skiebe, 1999). In the crab Carcinus maenas, 20 different peptides of the allatostatin superfamily have been isolated. They share homology in the $\mathrm{C}$ terminal sequence, but none is identical to any of the insect allatostatins (Duve etal., 1997c). Allatostatin immunoreactive (AST ir) neurons were identified in the stomatogastric nervous system of crustaceans. The only physiological effects of allatostatins reported for crustaceans are slowing of the pyloric rhythm (Skiebe \& Schneider, 1994) and a decrease of the gain of neuromuscular transmission in stomach muscles (Jorge Rivera \& Marder, 1997).

In adult insects and crustaceans, only visceral and heart muscles were known to be innervated and modulated through AST ir neurons, although motor neurons supplying maxillary and thoracic skeletal muscles in larvae of Manduca sexta show AST immunoreactivity (Davis et al., 1997). We recently detected AST immunoreactivity on skeletal muscles of the locust (Kreissl et al., 1995) and on fibres of the 
dorsal extensor muscles in the crustacean Idotea. These findings suggest that allatostatin may act as a modulatory peptide on skeletal muscles of arthropods.

Investigating this peptidergic innervation, we discovered in Idotea a set of AST ir motor neurons supplying identified skeletal muscle fibres and found novel mechanisms of action. Allatostatin exerts two complementary inhibitory effects: presynaptically, it reduces evoked transmitter release from excitatory neuromuscular terminals and, postsynaptically, it decreases the contraction of muscle fibres.

\section{Materials and methods}

\section{Animals}

Experiments were performed on the isopods Idotea baltica and Idotea emarginata and the crab Eriphia spinifrons. The isopods were obtained from the Zoological Station in Naples, Italy and from the Biologische Anstalt Helgoland, Germany. The crabs were collected in Naples. In Konstanz, the animals were kept in artificial seawater at $16^{\circ} \mathrm{C}$.

\section{Preparations and solutions}

In Idotea, the dorsal extensor muscles from the pereion segments (i.e. the free thoracic segments bearing legs) of adult males of $1015 \mathrm{~mm}$ body length were used. After anaesthetizing the animal by chilling, the head and the legs were removed. To expose the dorsal extensor muscle fibres, the specimen was pinned ventral side up on Sylgard. Pereion sternites with attached flexor muscles and the ventral nerve cord were cut away. The gut, the tubes of the digestive gland, the gonads with the vasa deferentia and the heart were removed.

The saline had a composition of (in $\mathrm{mM}$ ) $\mathrm{NaCl}, 490 ; \mathrm{KCl}, 8 ; \mathrm{CaCl}_{2}$, $10 ; \mathrm{MgCl}_{2}, 12$; HEPES, 10, at $\mathrm{pH}$ 7.4. Allatostatin 1 and 3 were purchased from Sigma (Deisenhofen, Germany). They are now termed Dip AST 7 and Dip AST 8, respectively (Gäde et al., 1997). The peptides were dissolved in distilled water at $1 \mathrm{~mm}$ concentration and stored at $20^{\circ} \mathrm{C}$. Stock solution aliquots were diluted in saline prior to experiments. The peptide containing solutions were applied to the bath by means of a switching port of the superfusion system (contraction measurements) or through a pipette (excitatory junc tional potential/EJP recordings). For macropatch recordings from single release sites, solutions were applied by pressure through a microperfusion system of the electrode (for details see Dudel, 1989).

The experiments were carried out at room temperature or at $18^{\circ} \mathrm{C}$ (contraction recordings).

\section{Immunostaining}

For identification of Dip AST 7 immunoreactive (Dip AST 7 ir) neurons, body halves or isolated ventral nerve cords were fixed in $4 \%$ paraformaldehyde in $0.1 \mathrm{M}$ phosphate buffer at $\mathrm{pH} 7.4$ for $24 \mathrm{~h}$ at $4{ }^{\circ} \mathrm{C}$. After washing, permeabilizing and blocking of nonspecific binding of antibodies, the specimens were incubated in a $1: 2.000$ solution of the polyclonal anti Dip AST 7 serum (Vitzthum etal., 1996) in phosphate buffered saline containing $0.5 \%$ Triton $X 100$ with $0.2 \%$ BSA. After washing, the tissue was treated either by incubation in a $\mathrm{Cy}^{3}$ conjugated goat antirabbit $\operatorname{IgG}(1: 500$, Jackson ImmunoResearch Laboratories, West Grove, PA, USA) or by binding the primary antiserum with the $\mathrm{ABC}$ kit (Vector Laboratories, Burlingame, CA, USA). To confirm the findings from whole mount preparations, serial sections of the ventral nerve cord and dorsal extensor muscles were analysed. The preparations were fixed $4 \mathrm{~h}$ in an ice cold solution of $4 \%$ paraformaldehyde and $0.5 \%$ glutaralde hyde in $0.1 \mathrm{M}$ phosphate buffer at $\mathrm{pH}$ 7.4. After washing, they were dehydrated, cleared in xylene and immersed in paraplast overnight. Immunostaining was performed on $12 \mu \mathrm{m}$ sections using the ABC method following the protocol for whole mount preparations but with shorter incubation times. The primary antiserum was diluted $1: 10.000$. After dehydration, the sections were cleared in xylene and mounted in Entellan (Merck, Darmstadt, Germany).

\section{Backfills and double labelling experiments}

To identify Dip AST 7 ir motor neurons innervating the extensor muscle fibres, retrograde axonal filling with Lucifer Yellow (Molecular Probes, Eugene, OR, USA) was combined with antibody labelling. The isolated nerve cord, with nerves N1 to N3 attached, was pinned on a Sylgard coated dish filled with saline. The cut end of N3B was lifted into a small Vaseline pot filled with a 3.5\% solution of Lucifer Yellow in distilled water, and then sealed with Vaseline. Enough saline was added to keep the specimen wet. Diffusion and retrograde transport of Lucifer Yellow was allowed to take place at room temperature for $1 \mathrm{~h}$. The nerve cord was then fixed in $4 \%$ paraformaldehyde in $0.1 \mathrm{M}$ phosphate buffer at $\mathrm{pH} 7.4$ for $24 \mathrm{~h}$. For double labelling, Lucifer Yellow filled preparations were immunos tained as described above.

\section{Tension measurements}

Contraction studies were performed on Idotea with the short extensor fibre 2 of pereion segment 7 . This segment was excised by cutting the anterior intersegmental membrane and by transecting pleon segment 1. The isolated preparation, containing a complete set of the four short fibres 14 , was transferred to a temperature controlled $0.5 \mathrm{~mL}$ bath. The posterior end of the preparation was attached to a miniforceps mounted on a micromanipulator. The fibres were stretched to in situ resting length. The bath was continuously perfused with precooled saline $\left(18^{\circ} \mathrm{C}\right)$ at a flow rate of $0.5 \mathrm{~mL} / \mathrm{min}$.

The contraction force of single fibres was registered isometrically by means of a force transducer KG3 (Scientific Instruments Güth, Heidelberg, Germany) which was connected to the anterior segmental rim with a small pin, and its output was fed into a bridge amplifier (Scientific Instruments Güth, Heidelberg, Germany). Contractions were evoked by constant current or voltage clamp stimulation. Prior to each peptide application, at least three control measurements were made. Only preparations with a consistent peak value of muscle tension upon identical depolarization steps were used.

For current injection and voltage measurements, an AxoClamp 2B amplifier (Axon Instruments, Foster City, CA, USA) was used. Intracellular electrodes were filled with a $1: 1$ mixture of $3 \mathrm{M} \mathrm{KCl}$ and $3 \mathrm{M} \mathrm{K}^{+}$citrate and had DC resistances between 2 and $5 \mathrm{M} \Omega$. To reduce capacitative coupling between the two electrodes, a grounded shield was placed between them.

\section{Macropatch recordings: Idotea}

For macropatch recordings of excitatory junctional currents (EJCs), fibre 5 from pereion segments 6 and 7 was used. The preparation for exposing the fibres was identical to that described above, but the segment containing the muscles to be studied was not excised. The preparation was kept in a small continuously perfused Sylgard chamber. In experiments where transmitter release at individual neuromuscular junctions was not stimulated by depolarizing pulses through a macropatch electrode (see below), nerve N3 (Fig. 1C) of pereion ganglion 5 or 6 was stimulated through a suction electrode with single pulses at 0.5 or $1 \mathrm{~Hz}$. For these experiments, animals anaesthetized by chilling were divided near the midline leaving the ganglia of the ventral nerve cord intact in one half. The half segments were split and 

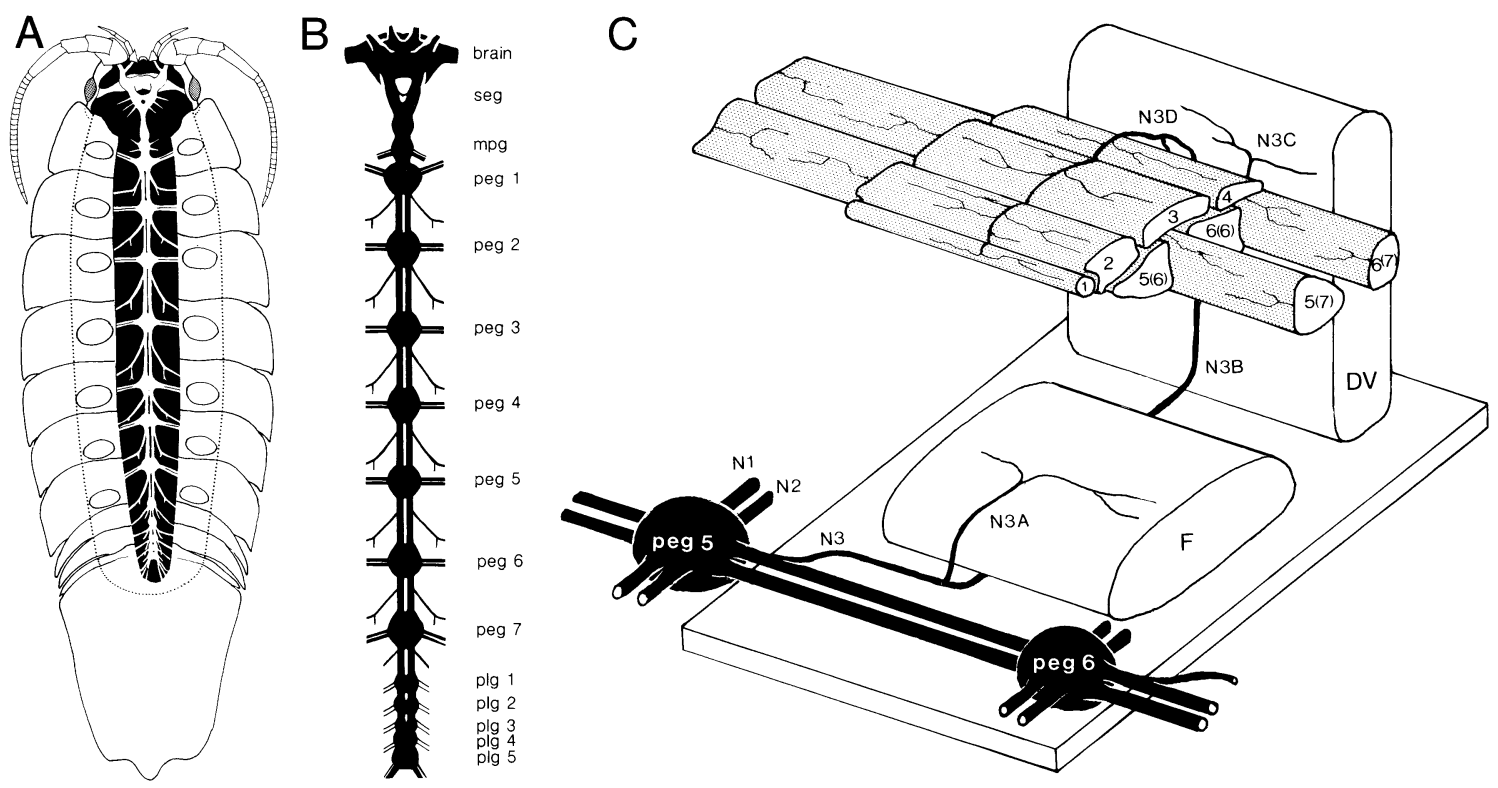

FIG. 1. Schematic representation of the nervous system and the dorsal extensor muscle fibres of Idotea baltica. (A) Male of $2 \mathrm{~cm}$ body length. Ventral view, opened to show the central nervous system; legs (circles in pereion segments) removed. Drawing by M. Häberle. (B) Isolated ventral nerve cord with ganglia and their main nerves. The numbers indicate the pereion and pleon segments in which the ganglia are located. (C) Schematic drawing of the muscles within a typical half segment of the pereion with emphasis on the dorsal extensor muscle (stippled fibres). The extensor muscle in the half segment shown (segment 6) consists of eight fibres: four short fibres (1 4) and two long fibres originating in this segment and extending into the adjacent anterior segment [fibres 5(6) and 6(6)], and two long fibres spanning into this segment but originating in the posterior segment 7 [fibres 5(7) and 6(7)]. Innervation of the fibres of segment 6 is provided through nerve $\mathrm{N} 3 \mathrm{D}$ which is a branch of N3 leaving from the connective of the pereion ganglion located in segment 5. Anterior is shown to the left. DV, lateral dorsoventral muscle; F, ventral flexor muscle; mpg, maxillipedal ganglion; peg, pereion ganglion; plg, pleon ganglion; seg, subesophageal ganglion. N1, N2and N3, segmental nerves. N3A D, branches of N3.

pinned ventral side up in a Sylgard dish. This preparation was also used for intracellular recordings of EJPs.

For extracellular recording of EJCs generated at individual release sites, macropatch electrodes with opening diameters of $1015 \mu \mathrm{m}$ and DC resistances of $0.10 .3 \mathrm{M} \Omega$ were filled with saline. The signals were recorded through an amplifier designed for recording from, and stimulating, individual release sites (Zeitz Instruments, Augsburg, Germany). Optimal release sites producing fast rising EJCs, and with occurrence of single spontaneously released quanta of an amplitude of $\approx 500 \mathrm{pA}$ were found by trial and error by moving the recording electrode along the length of the fibres while delivering depolarizing current pulses of $0.10 .5 \mathrm{~ms}$ duration and $28 \mu \mathrm{A}$ amplitude through the patch electrode (Dudel, 1981). The electrode could be pressure perfused with different test solutions as described by Dudel (1989).

Seal resistance was monitored by applying a test current pulse through the electrode. Only experiments in which seal resistance did not change by $>5 \%$ throughout the experiment were used for further analysis.

\section{Eriphia}

Electrophysiological studies were performed on identified slow contracting fibres (Rathmayer \& Maier, 1987) of the closer and opener muscles of walking legs. Preparation, composition of the muscles of different fibre types and methods for stimulation of individual axons (closer: the slow and the fast excitor SCE and FCE; opener: the excitor $\mathrm{OE}$ ) have been described (closer: Rathmayer \& Erxleben, 1983; opener: Wiens et al., 1988). In the closer, we used fibre 2, rarely fibre 3, and in the opener the three most distal fibres. Evoked EJCs from individual release sites were recorded extra cellularly using the focal macropatch technique (see above). Analysis of quantal parameters of transmitter release was performed for the SCE. The mean quantal content $(m)$ of EJCs was determined directly by counting single quanta and comparison with the number of trials. The number of putative release sites $(n)$ and the mean probability for release at the recorded site $(p)$ were calculated by adopting binomial statistics (Zucker, 1973; Cooper etal., 1995). Usually, at least 500 samples were analysed.

For FCE and OE, the quantal content of the EJCs was higher than with SCE (0.7 for SCE, 710 for FCE, 1215 for OE) and varied little in a given experiment. Therefore, with $0.5 \mathrm{~Hz}$ stimulation, 250500 EJCs were averaged electronically.

\section{Data acquisition}

Pulse protocols and data acquisition for contraction measurements were controlled by a DigiData 1200 interface (Axon Instruments Inc., Foster City, CA, USA) connected to a PC. Data were analysed using pClamp (Axon Instruments Inc.) and Origin (Microcal ${ }^{\mathrm{TM}}$ Software Inc., Northampton, MA, USA) software. Neurally evoked EJPs were recorded on a digital storage oscilloscope (Type 1425, Gould, Essex, UK). EJCs recorded with macropatch electrodes were either stored on tape (Racal 4 DS, Hythe, UK) or on a PC using an interface and patchclamp software ISO 2 (M. Friedrich, Niedernhausen, Germany).

\section{Results}

\section{Nervous system and innervation of extensor muscle fibers of Idotea}

The central nervous system of Idotea (Fig. 1A and B) resembles that of malacostracan crustaceans (Walker, 1935). It consists of 20 ganglia corresponding to the neuromeres of the 20 segments making up the body. The brain consists of three fused neuromeres (the proto , deuto and tritocerebrum) and is tilted into a dorsoventral axis above the esophagus. The first ganglion of the ventral nerve cord is the 
subesophageal ganglion which also consists of three fused ganglia (of the mandibular and the first and second maxillar segments). It is followed by eight thoracic ganglia: the first is the maxillipedal ganglion in the first thoracic segment which is fused with the six head segments to form the cephalothorax. The following seven thoracic segments are free to move and form the pereion. Each segment contains a separate ganglion (peg 17 , see Fig. 1B). The pleon consists of six segments of which only segments 1 and 2 are free to move, the others are fused to form the pleotelson. Of the corresponding six ganglia in the pleon, the first 4 are separate (plg 14 in Fig. 1B). The last two are fused to form the terminal ganglion (plg 5, Fig. 1B). The pereion segments bear uniramous legs (pereiopods). The pleon segments also bear legs, the first pair modified as gonopods and the next four having rami functioning as gills, and the last being large plates covering the gills.

All pereion ganglia (Fig. 1C) have three main pairs of nerves (N1, $\mathrm{N} 2$ and N3) which exit laterally. N1 and N2 originate in the ganglion and supply the extrinsic and intrinsic muscles of the pereiopods. They also contain the sensory afferents from the body wall, endopodite and exopodite (Okada \& Kuwasawa, 1995, shown for the isopod species Bathynomus doederleini). N3 branches posterolaterally from the connective. In each segment, N3 innervates the ventral flexor, the dorsal extensor muscles and part of the musculature of the lateral body wall. Whereas $\mathrm{N} 1$ and $\mathrm{N} 2$ of a particular pereion ganglion supply the muscles of the legs belonging to the same segment, N3 has its targets in the adjacent posterior segment; e.g. N3 of pereion ganglion 5 supplies muscles in pereion segment 6 (Fig. 1C).

Each pereion segment and the first two pleon segments contain bilaterally symmetric dorsal extensor muscles. The number of fibres composing a single extensor muscle differs, but is characteristic for each segment. Three to five fibres are short and confined to that segment (e.g. in pereion segment 6 the fibres numbered 14 in Fig. 1C). In pereion segments 15 , one additional long fibre spans two segments by extending into the adjacent anterior segment and is thus also part of the fibre set in that segment. In pereion segments 6 and 7 and in pleon segments 1 and 2, two long fibres extend anteriorly into the adjacent segment, e.g. the fibres 5 (6) and 6 (6) in Fig. 1C (the number in parenthesis refers to the segment in which the fibre originates).

In summary, pereion segment 1 contains five fibres (three short, two long), pereion segments 2, 3 and 4 have six (four short, two long), pereion segment 5 contains eight (five short, three long) and pereion segments 6 and 7 as well as pleon segments 1 and 2 each contain eight fibres (four short, four long).

\section{Distribution of Dip-AST-7-ir axons on extensor muscle fibres in Idotea}

In all pereion segments, Dip AST 7 ir axons accompany the long extensor muscle fibres. On the short extensor fibres, Dip AST 7 immunoreactivity was not detected. The immunoreactive axons run on the surface of the long fibres and extend with them at least into the neighbouring segments. Along their course these axons form many varicosities (Fig. 2A) and give rise to a few branches which are restricted to the long fibres. In the pereion segments 26 , these branches form flat bouton like endings (Fig. 2B) in the regions of the anterior segmental boundaries.

The immunoreactive innervation is supplied through nerve N3D (Fig. 2C) which branches from N3 (Fig. 1C). In each N3D, except the one containing the axons from peg 4, a single Dip AST 7 ir axon was detected in whole mount preparations (Fig. 3C) and in serial sections. When N3D contacts the long muscle fibres (Fig. 2C), the axon divides and projects anteriorly and posteriorly and joins the immunoreactive axons originating from $\mathrm{N} 3 \mathrm{D}$ of neighbouring segments. In the pereion segment 7 and the pleon segments 1 and 2, a dense meshwork of varicose immunoreactive processes is present on the long muscle fibres (Fig. 2D). Some of the varicose processes originate from anterior segments. This meshwork does not appear to be directly attached to the muscle fibre and may be a neurohaemal release site for allatostatins.

\section{Dip-AST-7-ir neurons in the ventral nerve cord of Idotea}

Each pereion ganglion contains 1016 Dip AST 7 ir somata. Of these, one pair in the anterior lateral part of the ganglion is particularly prominent because of the large size (diameter, $3035 \mu \mathrm{m}$ ) and the staining intensity of the cells (Fig. 3A and B). This immunoreactive pair was never seen in segments 4 and $6(n=30)$. All the other somata (i.e. eight to 14 in each ganglion) stain with variable intensity and their localization varies depending on the segment (see schematic representation, Fig.4). Numerous Dip AST 7 ir processes ramify throughout each ganglion (Fig. 3C). Their density is higher in the posterior than in the anterior part. In addition, at least five immunoreactive axons run through each connective (Fig. 3C). One of these axons apparently traverses all ganglia of the pereion in a dorsal tract.

In pereion segments 13 and 5 7, one immunoreactive axon leaves the corresponding ganglion on each side through N3 (Fig. 3C). In whole mount preparations, this axon could be traced into N3D supplying the extensor muscle fibres, but because of the numerous immunoreactive varicosities and branches in the neuropil, it could not be traced to any of the stained somata. In order to identify the soma of this Dip AST 7 ir motor innervation, double labelling experiments were performed.

\section{Backfills and double labelling of neurons}

Unilateral backfills of nerve N3B with Lucifer Yellow stained up to 21 somata distributed over three neighbouring pereion ganglia (up to 18 in the corresponding segmental ganglion, one cell in the adjacent anterior and two cells in the adjacent posterior ganglion). In each pereion ganglion, a prominent pair of cells was stained in the anterior lateral halves. In pereion ganglia 2, 3 and 5, subsequent treatment with the allatostatin antiserum revealed a single double stained ipsilateral cell body in this position (Fig. 5). This cell is one of the large, immunostained pair described above. In pereion ganglia 1 and 7, the pair of anterior lateral Dip AST 7 ir neurons and the stained axon in $\mathrm{N} 3$ were consistently found. In pereion ganglion 6 , the immunoreactive axon leaving the ganglion through $\mathrm{N} 3$ is also present. As a corresponding immunoreactive soma was not clearly detected in this ganglion, the origin of the stained axon is not clear yet. Thus we conclude that a homonomous pair of Dip AST 7 ir motor neurons is present in all pereion ganglia except 4 . Figure 4 summarizes the results in a schematic representation.

\section{Contraction measurements on individual extensor muscle fibres}

To investigate myomodulatory effects of allatostatins in Idotea, we recorded contractions of single short fibres (fibre 2 of the dorsal extensor muscle in the isolated pereion segment 7). These fibres have a diameter of $\approx 200 \mu \mathrm{m}$ and a length of $\approx 750 \mu \mathrm{m}$. Their resting membrane potential lies at $70 \pm 3 \mathrm{mV}(\mathrm{SD}, n=51)$. The input resistance varied in different preparations from 200 to $600 \mathrm{k} \Omega$. Under experimental conditions, graded depolarizations to potential values above the excitation contraction threshold (EC threshold) result in graded contractions. Depolarizations under current clamp or voltage clamp conditions showed an EC threshold of $40 \pm 6 \mathrm{mV}(n=40)$. Clamping the fibres from holding potentials between 75 and $70 \mathrm{mV}$ 

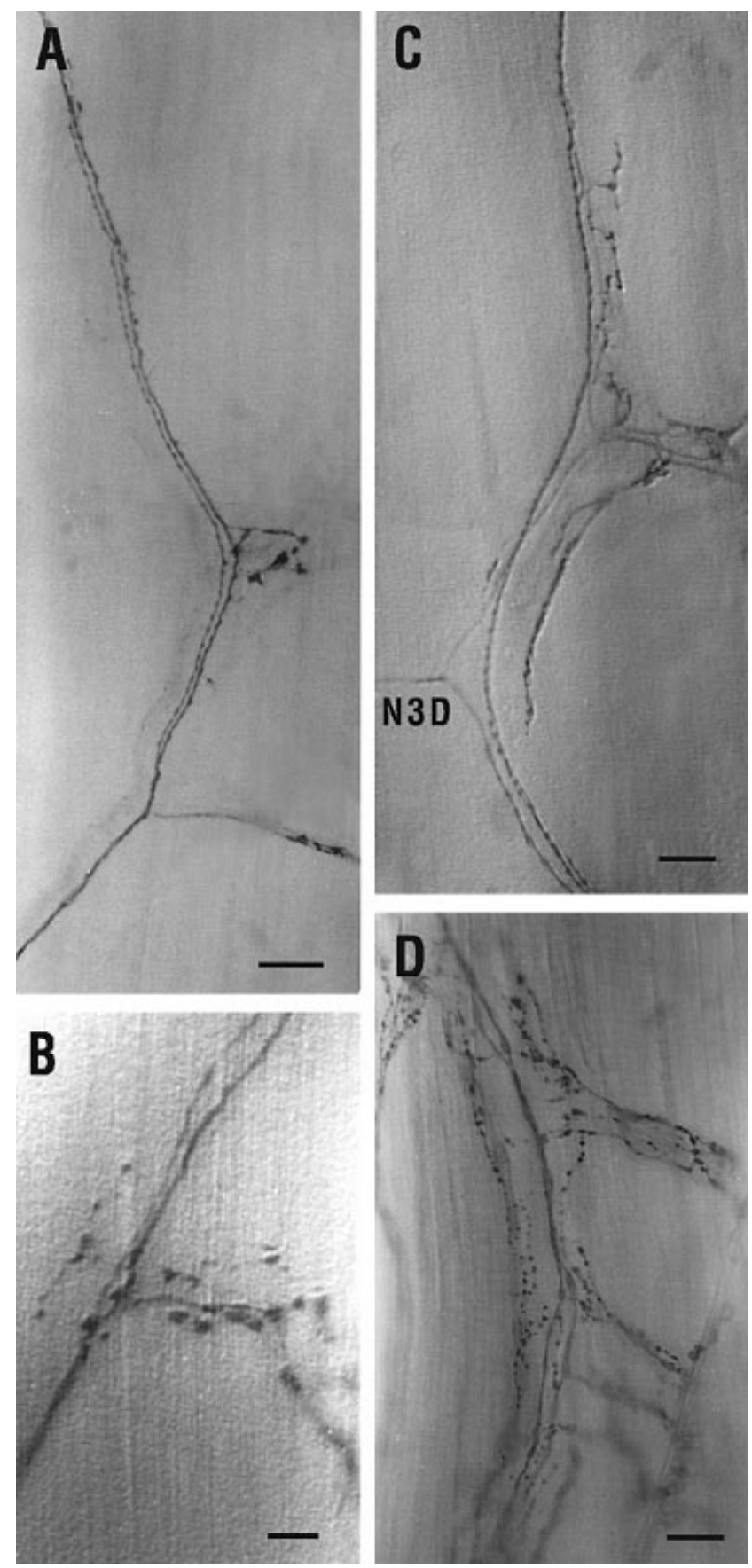

FIG. 2. Dip AST 7 ir axons on the long extensor muscle fibres in different segments of Idotea. Ventral views, anterior up and median to the right. (A) Two varicose Dip AST 7 ir axons run in parallel along muscle fibre 5(3) in pereion segment 3. (B) Dip AST 7 ir axonal branches on fibre 5(3) forming bouton like endings in the anterior part of segment 3. (C) Immunoreactive axons on muscle fibre 5(6) in pereion segment 6 with varicosities and branches. A single Dip AST 7 ir axon originates in N3D. (D) Dense meshwork of varicose immunoreactive axons along muscle fibre 5 in pleon segment 1. Scale bars, $50 \mu \mathrm{m}$ (A and C), $10 \mu \mathrm{m}$ (B) and $25 \mu \mathrm{m}$ (D).

to various values above EC threshold evoked graded contractions proportional to the depolarization steps (Fig. 6A left, B). Repeated contractions of the muscle fibres were frequently accompanied by a decrease in peak tension. To avoid this fatigue, fibres used to examine allatostatin effects were depolarized only moderately beyond EC threshold, resulting in contractions which did not reach maximal tension.
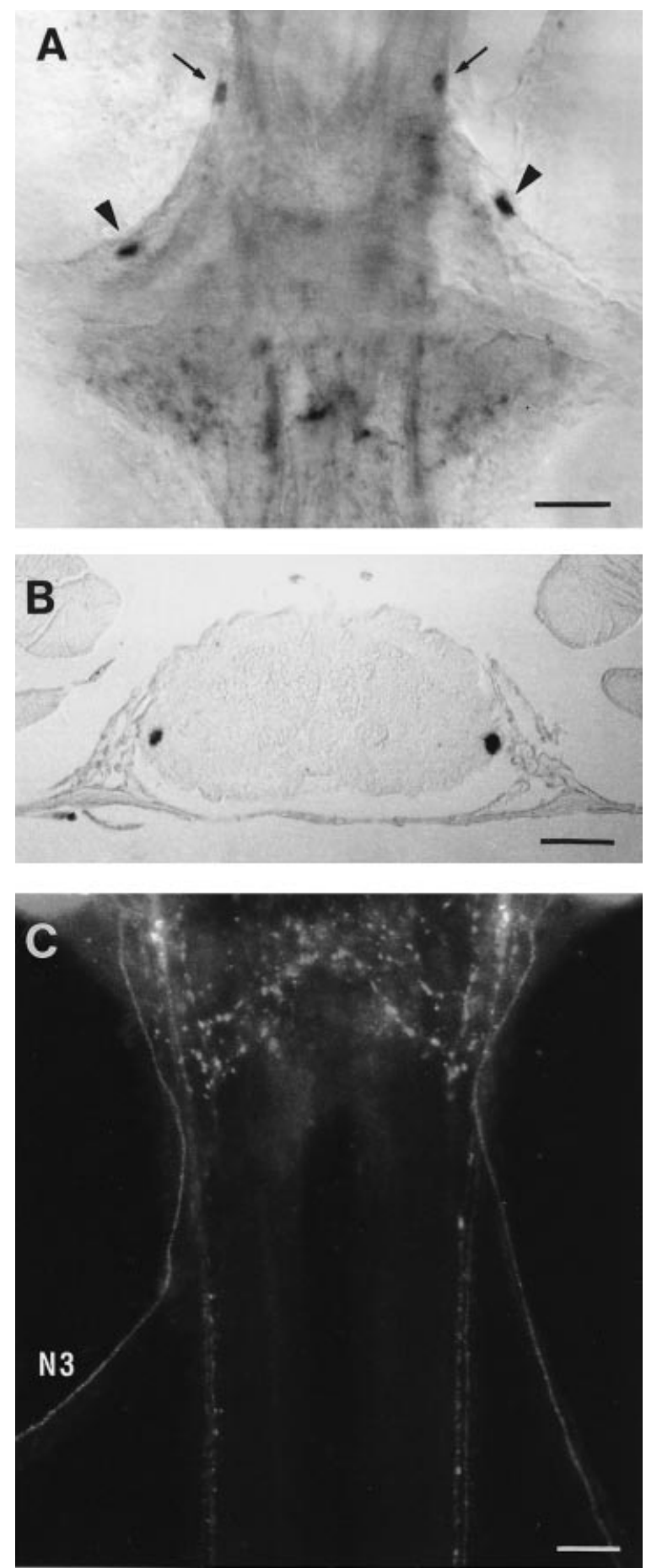

FIG. 3. Dip AST 7 immunoreactivity in ventral nerve cord of Idotea. (A) Dorsal view of pereion ganglion 2. A pair of large anterior lateral somata (arrowheads) and a pair of smaller somata (arrows) are seen. In this plane of focus, a dense array of varicose immunoreactive processes is restricted to the posterior region of the ganglion. (B) The pair of large anterior immunoreactive somata in a frontal cross section of pereion ganglion 3. (C) Whole mount preparation, showing the posterior end of pereion ganglion 3 and the connectives, from which nerves $\mathrm{N} 3$ branch. A single, immunofluorescent axon is seen in each N3, and several can be seen in the connectives. Scale bars, $100 \mu \mathrm{m}(\mathrm{A}$ and $\mathrm{B})$ and $50 \mu \mathrm{m}(\mathrm{C})$.

Addition of Dip AST 7 or 8 at concentrations of $10^{5} 10^{8} \mathrm{M}$ $(n=17)$ always resulted in a decrease of the contraction amplitude without changing EC threshold. A typical result for $10{ }^{6} \mathrm{M}$ Dip AST 


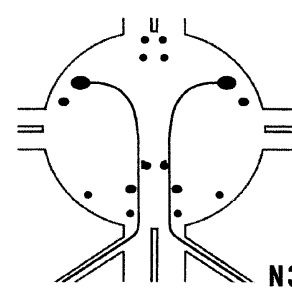

peg1

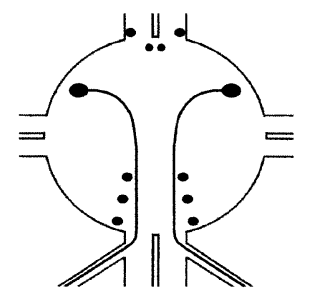

peg2
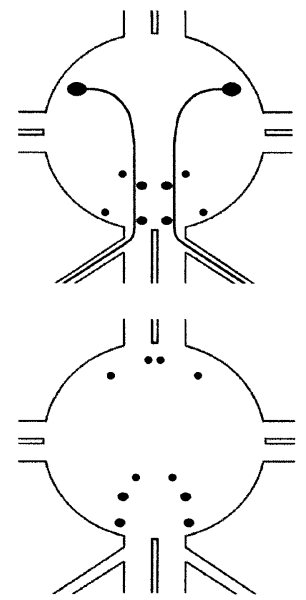

peg4
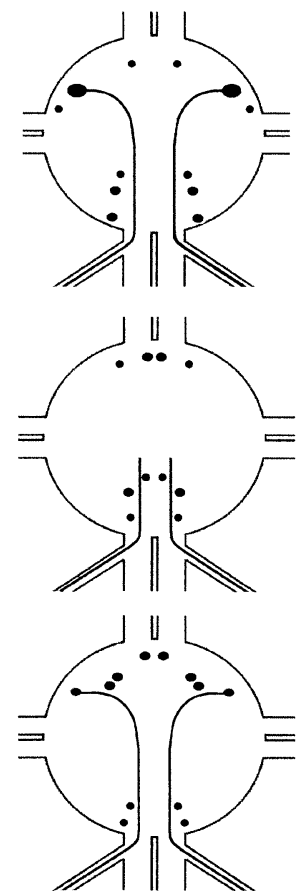

peg7

FIG. 4. Schematic representation of Dip AST 7 ir neurons in the pereion ganglia 17 of Idotea. Peg 1, 2, 3, 5, and 7 contain the paired Dip AST 7 ir motor neurons, whose axons exit through nerves N3. In peg 6, these axons are also present in $\mathrm{N} 3$, but the corresponding somata could not be assigned.

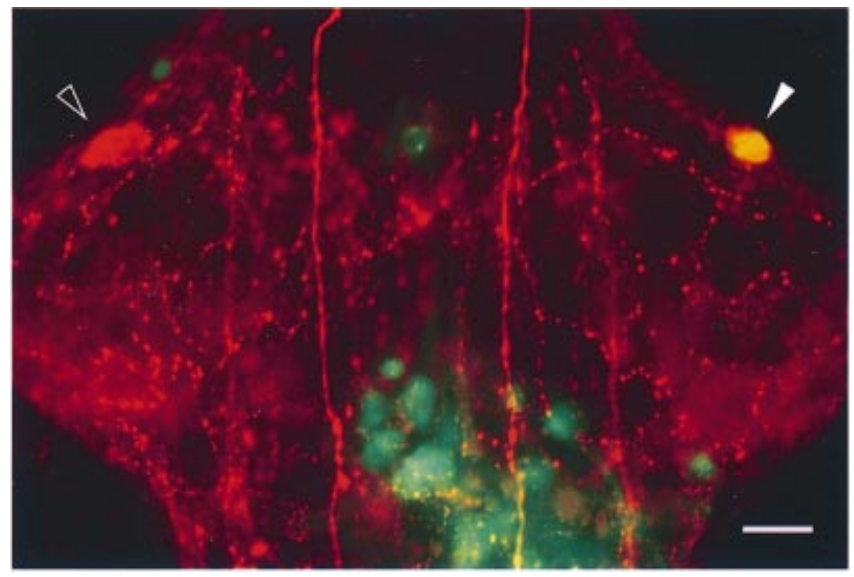

FIG. 5. Double labelling of a large anterior lateral soma in pereion ganglion 3. Motor neurons projecting into one of the N3B were backfilled with Lucifer Yellow (green). Dip AST 7 immunoreactivity in the pair of large anterior lateral somata (open and filled arrowheads) and in varicose axons was visualized by indirect immunofluorescence using a $\mathrm{Cy}^{3}$ conjugated secondary antibody (red). Yellow indicates double labelling of the large anterior motor neuron (filled arrowhead), ispilateral to the backfill, in the double exposure photomicrograph. Scale bar, $50 \mu \mathrm{m}$.

8 is presented in Fig. 6. The allatostatin effects occurred within minutes of application and persisted as long as the peptide was present (usually $10 \mathrm{~min}$ ). In four out of 17 experiments, the amplitude of evoked contractions returned to control levels after washing. In the others, the effects of allatostatin persisted for as long as $2 \mathrm{~h}$ of washing.

The contraction amplitude (measured at its peak) developed by individual fibres varied considerably among preparations. Figure 7A shows examples from six preparations in which, at similar voltage steps, muscle tension ranged from 65 to $275 \mu \mathrm{N}$ in the controls. In every case this tension was markedly decreased by $10{ }^{6} \mathrm{M}$ Dip AST 8. Pooling the data (Fig. 7B) shows a significant average reduction of tension by $48 \pm 8 \%$ of control (SD, $n=6, P \leqslant 0.001$, paired Student's $t$ test).

To determine whether the allatostatin induced decrease in the contraction amplitude was associated with changes in passive electrical membrane properties, fibres were current clamped in control saline and in the presence of allatostatin. As revealed from current voltage plots (not shown), allatostatin did not significantly alter input resistance $(P \leqslant 0.001$, paired Student's $t$ test). This excludes the possibility that the reduction of contraction amplitudes was caused by a decrease of the resting membrane permeability of the muscle fibres by the peptide. These findings are also documented in recordings of evoked EJPs. Dip AST $7\left(10^{6} \mathrm{M}\right)$ did not affect the resting membrane potential or the time course of decay of the EJPs, although it markedly reduced their amplitudes (Fig. 8A).

\section{Effects of allatostatin on transmitter release}

Application of Dip AST $8\left(10^{8} 10^{6} \mathrm{M}\right)$ onto synaptic terminals through the pressure perfused macropatch electrode always signifi cantly reduced the amplitude of evoked EJCs (Fig. 8B) by an average of $34 \pm 17 \%$ ( $n=9, P \leqslant 0.005$, paired Student's $t$ test).

The observed decrease in the EJC amplitudes could be due to an effect of allatostatin on parameters of transmitter release. It could also result from postsynaptic effects due to a reduction of the number of transmitter gated ion channels or a change in their sensitivity. To discriminate between pre and postsynaptic mechanisms, we simultaneously analysed the amplitudes of both the EJCs evoked 

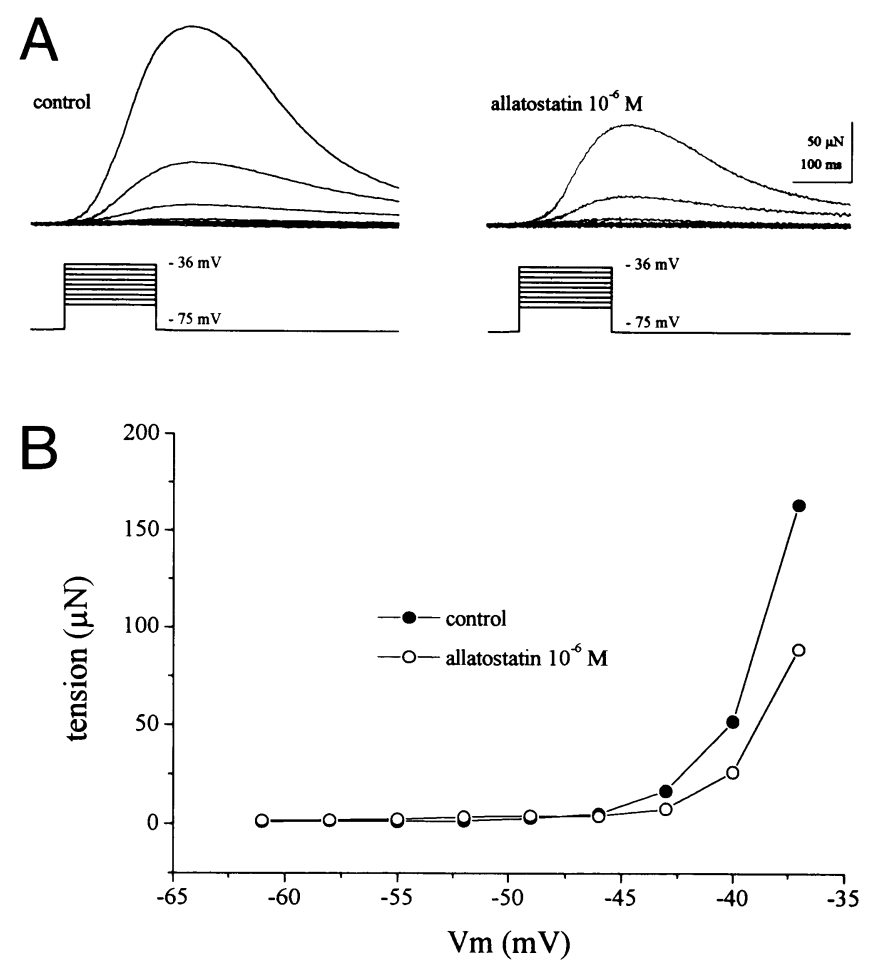

FIG. 6. Inhibitory effect of allatostatin on muscle tension in Idotea. (A) Records of graded contractions (upper traces) of a voltage clamped fibre 2 of pereion segment 7 upon voltage steps (lower traces) from a holding potential of $75 \mathrm{mV}$ to $36 \mathrm{mV}$ before (left) and $3 \mathrm{~min}$ after (right) application of $10{ }^{6} \mathrm{M}$ Dip AST 8. Allatostatin decreased peak tension without affecting EC threshold, which was $43 \mathrm{mV}$ in both sets of measurements. (B) Tension plotted as a function of membrane potential (same preparation as in A).

by macropatch stimulation and the miniature EJCs (mEJCs) caused by spontaneous release at the same site. Figure 9 shows typical results obtained from a fibre 5. In this experiment, $10{ }^{6} \mathrm{M}$ Dip AST 8 reduced the amplitude of the evoked EJCs by $48 \%$ (2.23 nA \pm 0.3 in control; $1.16 \mathrm{nA} \pm 0.3$ in allatostatin). The amplitude of the mEJCs, however, remained in the same range throughout the experiment $(0.4 \mathrm{nA} \pm 0.1$ in control; $0.39 \mathrm{nA} \pm 0.09$ in the presence of allato statin). The absence of allatostatin effects $(n=4)$ on the amplitude of mEJCs generated by spontaneously released single transmitter quanta in the presence of strong inhibitory effects of the peptide on EJCs suggests that the reduction of EJC amplitudes is due to a presynaptic effect (see also below).

The inhibitory effects of allatostatin could not be reversed within $30 \mathrm{~min}$ of washing. Washing for $1 \mathrm{~h}$ restored the original EJC amplitudes in only one experiment out of nine.

\section{Effects of allatostatin on parameters of evoked release in Eriphia}

The neuromuscular junctions on slow contracting fibres in leg muscles of the crab Eriphia permit a further analysis of the mechanisms underlying the inhibitory presynaptic effect of allatos tatin suggested by the results on spontaneous transmitter release in Idotea. Unlike to the situation in Idotea, the Eriphia preparation enables the selective stimulation of single identified excitatory axons. It is thus possible to analyse the effects of allatostatin on parameters of evoked transmitter release quantitatively. In addition, the two motor neurons (the slow and the fast excitor, SCE and FCE) providing double excitatory innervation to some fibres in the closer muscle, are of different functional type (Rathmayer \& Erxleben,
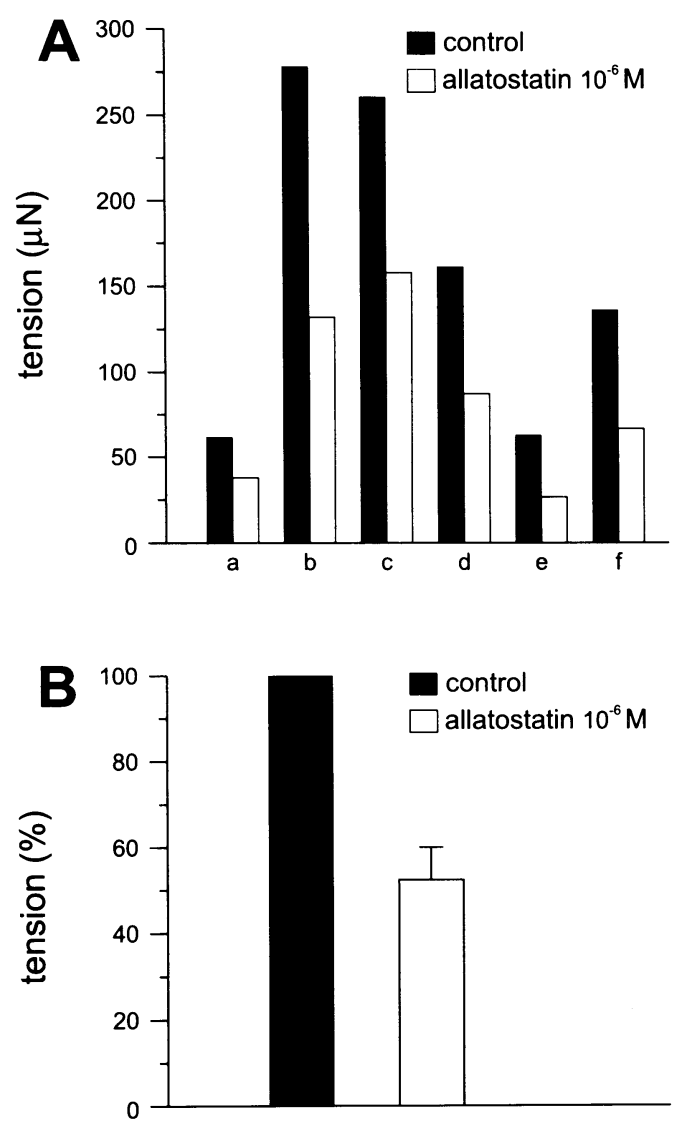

FIG. 7. Inhibitory effects of allatostatin on muscle tension of voltage clamped fibres 2 of pereion segment 7 in Idotea. (A) Variability of tension obtained in six different preparations (a $\mathrm{f}$ ) upon similar depolarization protocols in control saline and in the presence of $10^{6} \mathrm{M}$ Dip AST 8. (B) Normalized data of the six experiments shown in A plotted as the mean peak tension \pm SD.

1983). We also investigated whether allatostatin exerts its inhibitory modulatory effect on both types of motor neurons.

Allatostatin always decreased the amplitudes of EJCs in the opener and the closer muscle of Eriphia (Fig. 10). In the opener, the amplitudes of EJCs ranged from 2.5 to $8 \mathrm{nA}$. $10{ }^{6} \mathrm{M}$ Dip AST 7 decreased the averaged amplitudes significantly by $37.7 \pm 15.7 \%$ ( $n=3, P \leqslant 0.005$, paired Student's $t$ test). A typical result upon stimulation of the opener excitor OE is seen in Fig. $10 \mathrm{~A}_{2}$. The mean amplitude of $5.3 \mathrm{nA}$ in the control was reduced to $3.2 \mathrm{nA}$ in the presence of $10{ }^{6} \mathrm{M}$ Dip AST 7. When the EJCs are binned and the results plotted as a histogram (Fig. $10 \mathrm{~A}_{1}$ ), a shift to the left is evident.

A similar significant reduction of EJC amplitudes by allatostatin was seen with muscle fibres of the closer regardless of whether FCE or SCE was stimulated (Fig. 10B and C). In different experiments, the EJC amplitudes elicited by FCE ranged from 3 to $7 \mathrm{nA} .10{ }^{6} \mathrm{M}$ Dip AST 7 reduced the averaged amplitudes by $36.6 \pm 11.1 \% \quad(n=6$, $P \leqslant 0.005$, paired Student's $t$ test). The effect could be partially reversed by washing in only one experiment. But even in that experiment, the original amplitude of $5.7 \mathrm{nA}$ for the averaged EJCs was not fully regained after $25 \mathrm{~min}$ of washing (final amplitude $4 \mathrm{nA}$, $3.4 \mathrm{nA}$ in the presence of allatostatin). A typical example for FCE is presented in Fig. $10 \mathrm{~B}_{2}$. In this experiment, allatostatin reduced the averaged EJC amplitude by $51 \%$ (control $4.5 \mathrm{nA}$, in the presence of allatostatin $2.2 \mathrm{nA}$ ). The averaged amplitudes of EJCs elicited by stimulation of SCE were reduced in the presence of allatostatin by $21.5 \pm 6.4 \%(n=4, P \leqslant 0.001$, paired Student's $t$ test $)$. A macropatch recording from a SCE terminal is shown in Fig. $10 \mathrm{C}_{2}$. In this 

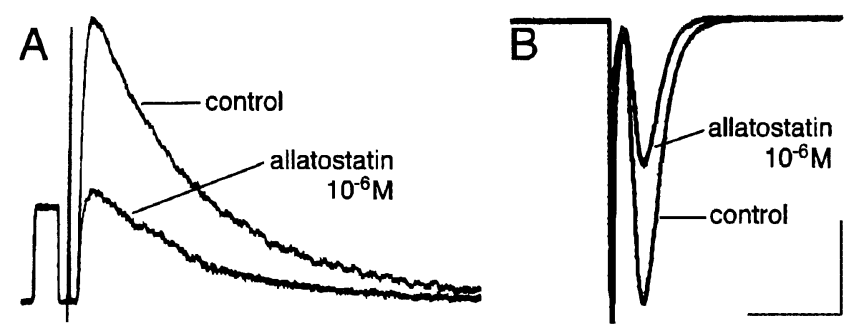

FIG. 8. Effect of allatostatin on EJPs and EJCs in Idotea. (A) EJPs of a fibre 2 in pereion segment 5, two traces superimposed. Eight EJPs averaged for controls and in the presence of $10^{6} \mathrm{M}$ Dip AST 7, which reduced the amplitude by $62 \%$. The membrane resting potential remained constant at $77 \mathrm{mV}$ throughout the experiment. (B) EJCs of a fibre 5 in pereion segment 7 , two traces superimposed. Each trace represents the average of 500 samples. Calibration pulse in A, $2 \mathrm{mV}$ and $10 \mathrm{~ms}$. Scale bars in $\mathrm{B}, 1 \mathrm{nA}$ and $5 \mathrm{~ms}$.

experiment, $10{ }^{6} \mathrm{M}$ Dip AST 7 decreased the average amplitude by $26 \%$ (control $2.7 \mathrm{nA}$, in allatostatin $2.0 \mathrm{nA}$ ).

As the amplitudes of spontaneously released single quanta (mEJCs, not shown) were not changed, the effects of Dip AST 7 are attributable to a presynaptic inhibitory effect on evoked transmitter release.

Through stimulation of the SCE, a direct quantal analysis of evoked transmitter release is possible by counting single quanta because of the small number of quanta released by each action potential. Thus, a quantitative determination of release parameters employing binomial statistics is feasible. The mean quantal content $m$ was directly determined as described in the methods section. Table 1 summarizes the results, giving the numbers of transmitter quanta released $(0,1,2,3$ or 4$)$ for $\approx 500$ trials in either controls or in the presence of $10^{6} \mathrm{M}$ Dip AST $8(n=4)$. It is evident that allatostatin increased the number of failures significantly. The number of release sites $n$ under the opening of the electrode was two in Experiment 1, and one in each of the other three experiments. This parameter was not affected by the peptide. Only the probability of release $p$ and therefore the mean number $m$ of quanta released were significantly reduced by the peptide (see Table 1 ). On average, $m$ was reduced by $36.3 \pm 9.4 \% \quad(P \leqslant 0.001$, paired Student's $t$ test $)$ and $p$ by $30.5 \pm 12.9 \%(P \leqslant 0.005$, paired Student's $t$ test $)$.

The EJC amplitudes elicited by single quanta in evoked release upon stimulation of SCE in the presence of allatostatin were not different from those in controls. This result parallels that observed for spontaneous release in Idotea. It proves that the reduction of EJC and EJP amplitudes by allatostatin observed in different muscles is indeed due to a presynaptic effect. Allatostatin reduces the mean number of transmitter quanta released by each action potential invading the terminals.

\section{Discussion}

\section{Immunocytochemical identification of Dip-AST-7-ir neurons}

In this study, immunoreactivity was detected using a polyclonal antiserum raised against allatostatin (Dip AST 7) from the cockroach Diploptera with the amino acid sequence APSGAQRLYGFGL $\mathrm{NH}_{2}$. In competitive ELISA tests, Vitzthum et al. (1996) demonstrated the specificity of this antiserum for five Dip allatostatins, with a sensitivity for Dip AST 7 (in their paper, Dip AST 1) two orders of magnitude higher than for the others.

Four of these allatostatins were shown to decrease the frequency of the pyloric rhythm in the crab Cancer borealis (Skiebe \& Schneider, 1994). Dip AST 8 (in their paper, Dip AST 3), with the sequence
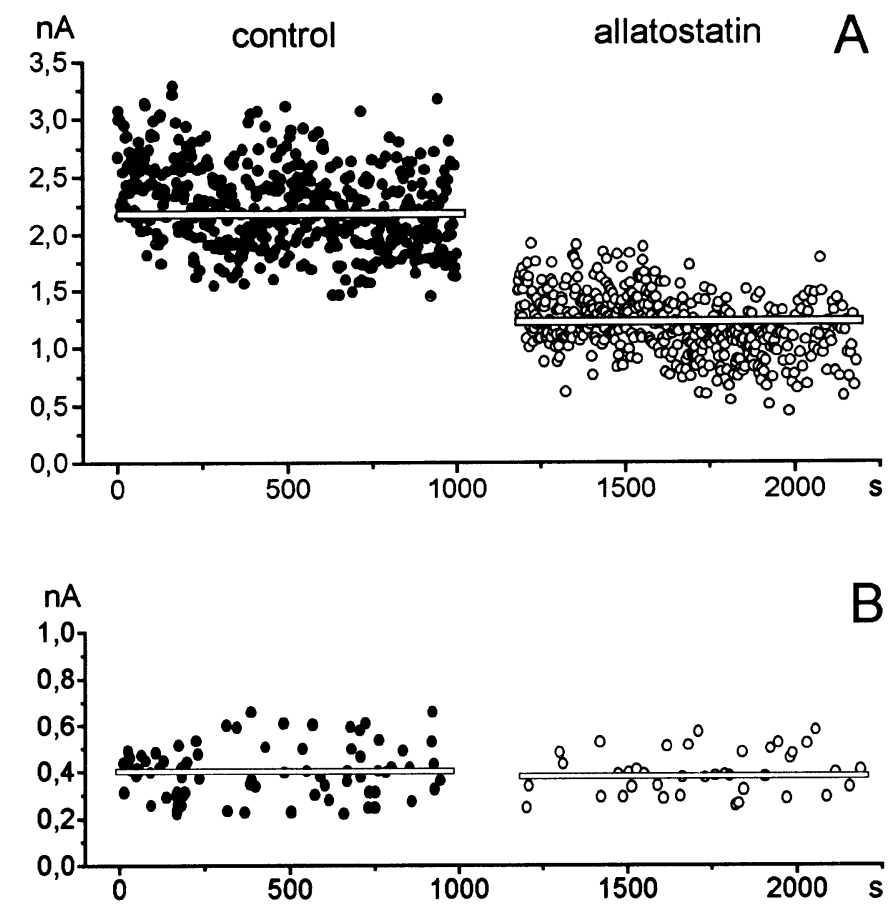

FIG.9. Inhibitory effect of allatostatin on evoked (A) and spontaneous (B) EJCs in Idotea. Continuous record over $2200 \mathrm{~s}$; after $1000 \mathrm{~s}, 10^{6} \mathrm{M}$ Dip AST 8 was applied to the preparation and stimulation and recording were interrupted for $200 \mathrm{~s}$. Evoked EJCs represent 500 samples in the control condition and in the presence of allatostatin.

GGSLYSFGL $\mathrm{NH}_{2}$, was only slightly more effective, whereas Jorge Rivera \& Marder (1997) found it decidedly more potent. Dip AST 7 and Dip AST 8, which we used for our physiological experiments, share leucine (L) as pretyrosyl (Y) residue and contain glycine $(\mathrm{G})$ or serine (S) as post tyrosyl residue. Recently, 20 neuropeptides of the allatostatin superfamily with the common $\mathrm{C}$ terminal pentapeptide sequence YXFGL $\mathrm{NH}_{2}$ were isolated from Carcinus maenas (Duve et al., 1997c). They contain either a post tyrosyl alanine (A) or serine (S) residue, the latter being identical with the post tyrosyl serine of Dip AST 8. We therefore conclude, despite the high concentration of antiserum used in our immunocytochemical protocols for whole mounts, that the immunoreactivity we found is indeed due to specific binding of the Dip AST 7 antiserum to a crustacean allatostatin of the subfamily sharing the YSFGL $\mathrm{NH}_{2}$ sequence, which is present and functional in Idotea. The concentrations of $10{ }^{6} \mathrm{M}$ needed to produce the physiological effects in our laboratory and in previous studies with crustaceans (Skiebe \& Schneider, 1994; Jorge Rivera \& Marder, 1997) might be explained by sequence differences in the $\mathrm{N}$ terminal between Diploptera allatostatins and those present in crustaceans.

The Dip AST 7 ir neurons identified in the nerve cord of Idotea showed considerable variations in staining intensity and position, depending on the ganglion and preparation. Segmental pairs of large, intensely stained neurons are the only Dip AST 7 ir motor neurons supplying skeletal muscles. These neurons were identified in all pereion ganglia except in segments 4 and 6 . By backfilling N3 in pereion ganglion 4 , a homonomous pair was consistently found, but it never showed Dip AST 7 immunoreactivity. This raises the question whether these paired motor neurons contain allatostatin as their only transmitter or whether allatostatin is a cotransmitter which is absent or replaced by another modulator in the pair of segment 4 .

The absence of the paired Dip AST 7 ir motor neurons in pereion ganglion 4 does not imply that the extensor muscles in the 

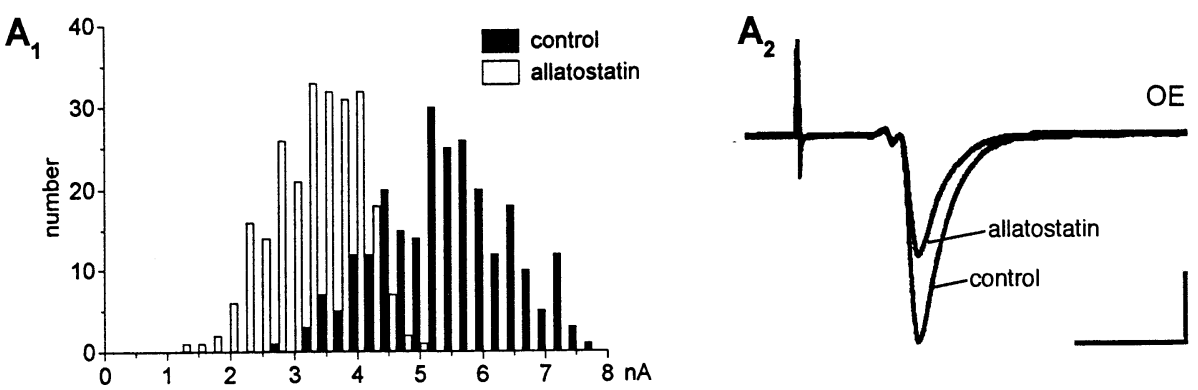

FIG. 10. Effect of allatostatin on evoked EJCs at individual release sites in Eriphia muscle fibres. $\left(A_{1} C_{1}\right)$ Amplitude histograms of EJCs with bin widths of $0.33 \mathrm{nA} .\left(\mathrm{A}_{2} \mathrm{C}_{2}\right)$ Averaged EJCs, two traces superimposed. (A) Opener muscle, 250 samples each for controls and in the presence of $10{ }^{6} \mathrm{M}$ Dip AST 7 after stimulation of $\mathrm{OE}$. (B) Closer muscle, stimulation of FCE, 360 samples in controls and with $5 \times 10^{6} \mathrm{M}$ Dip AST 7. (C) Closer muscle, SCE stimulated with twin pulses, $33 \mathrm{~ms}$ apart. Only the second, facilitated response used for averaging is shown: 500 samples for controls and with $10^{6} \mathrm{M}$ Dip AST 7. Calibrations, $2 \mathrm{nA}$ and $5 \mathrm{~ms}\left(\mathrm{~A}_{2}\right.$ and $\left.\mathrm{C}_{2}\right)$ and $10 \mathrm{~ms}\left(\mathrm{~B}_{2}\right)$.
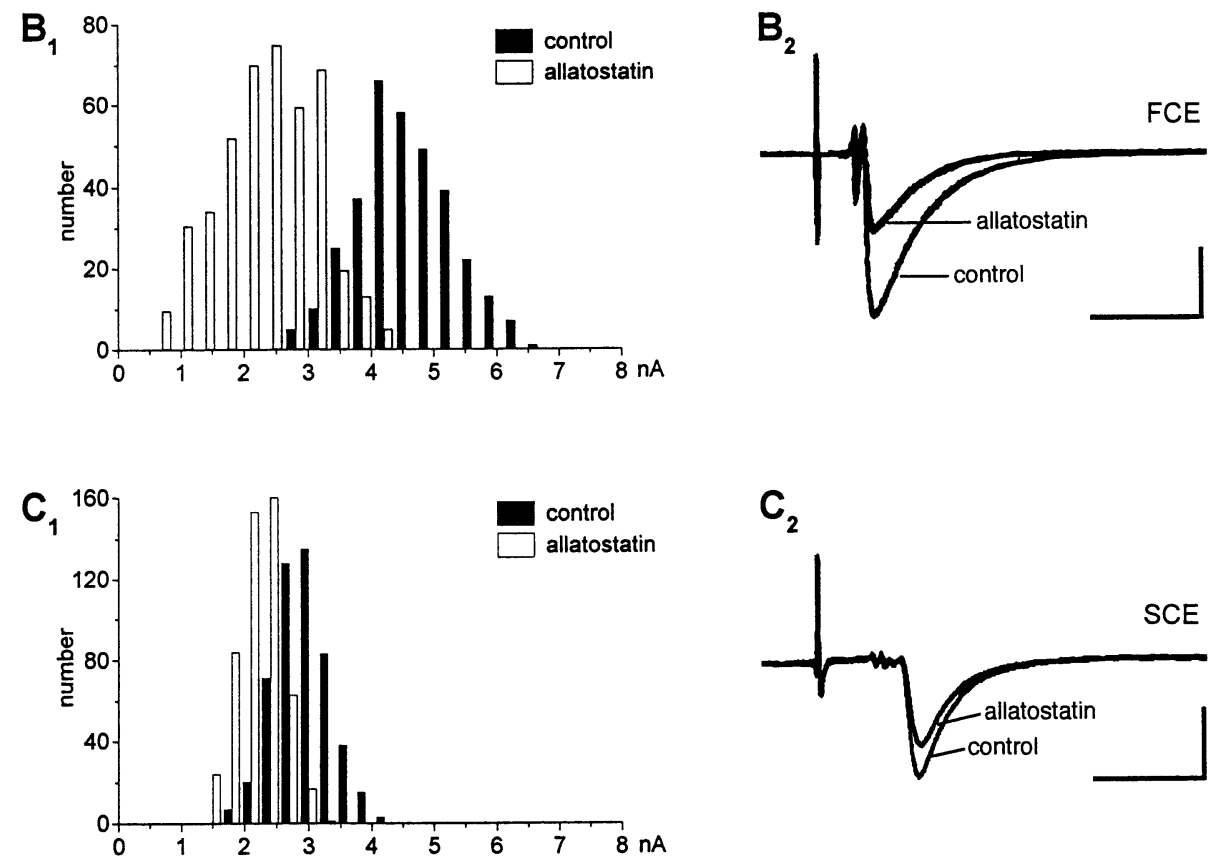

corresponding segment 5 lack this peptidergic innervation. This segment is supplied through immunoreactive axons originating from neighbouring segments.

\section{How does allatostatin reach its targets?}

Dip AST 7 ir axons were detected in Idotea only on the long fibres of the extensor muscles which span two segments. Immunoreactivity was absent on the short fibres. However, the short fibres responded to allatostatin in the same way as the long fibres. Allatostatin may reach the short fibres from sources other than neuromuscular contacts of Dip AST 7 ir neurons. A mesh work of immunopositive varicosities is present in the pleonal segments of the animal on the long muscle fibres. This could act as a neurohaemal organ, releasing allatostatin into the haemo lymph for distribution to the targets via diffusion and circulation. Varicosities in the perineurium or part of the immunoreactive endings on long muscle fibres in pereional segments could also be neurohaemal sources, as could the sinus gland or pericardial organs. In the crab Eriphia, we do not know the sources of allatostatin. However, neurohaemal release sites for allatostatin, e.g. the pericardial organs, have recently been described in several decapod crustaceans including a crab (Skiebe, 1999). Neurohaemal release of modulatory peptides appears to be widespread in crustaceans (Siwicki etal., 1985; Stangier et al., 1986; Kobierski etal., 1987; Abel etal., 1994; Skiebe \& Schneider, 1994; Trube etal., 1994; Christie etal., 1995; Jorge Rivera \& Marder, 1997).

\section{The action of allatostatin on EJCs is due to presynaptic effects}

We show that allatostatin decreases the amplitude of evoked EJCs but does not change the size of miniature EJCs resulting from spontaneous release of single transmitter quanta or the amplitude of EJCs generated by single quanta in evoked release. This proves a presynaptic mechanism of action.

This presynaptic effect of allatostatin on neuromuscular junctions of skeletal muscles represents a mechanism which differs from that postulated for stomach muscles of the crab Cancer borealis (Jorge Rivera \& Marder, 1997). In this animal, several allatostatins, most prominently Dip AST 8 (in their paper termed D AST 3), at concentrations of $10{ }^{6} \mathrm{M}$ reduce the amplitude of EJCs and, as a consequence, the amplitude of contractions upon motor axon stimulation. This inhibitory effect, however, is believed to be produced by a postsynaptic mechanism through modification of the transmitter receptors because allatostatin also reduced the amplitude of currents generated by ionophoretic application of glutamate and acetylcholine, the transmitters released at these muscles (Jorge Rivera \& Marder, 1997).

\section{Effects of allatostatin on contractions}

In addition to the presynaptic effect on neuromuscular transmission, allatostatin also causes inhibitory effects on the postsynaptic target, the muscle fibres. Contractions elicited by direct stimulation of single muscle fibres under current and voltage clamp conditions are 
TABLE 1. Effect of $10{ }^{6} \mathrm{M}$ Dip AST 8 on quantal release from SCE endings at neuromuscular junctions of the closer muscle of the crab Eriphia

\begin{tabular}{|c|c|c|c|c|c|c|c|c|c|c|}
\hline & \multirow[b]{2}{*}{ Experiment } & \multirow[b]{2}{*}{ Trials } & \multicolumn{5}{|c|}{ Quanta released } & \multirow[b]{2}{*}{$m( \pm \mathrm{SE})$} & \multirow[b]{2}{*}{$p( \pm \mathrm{SE})$} & \multirow[b]{2}{*}{$n( \pm \mathrm{SE})$} \\
\hline & & & 0 & 1 & 2 & 3 & 4 & & & \\
\hline 1 & Allatostatin & 488 & 102 & 312 & 68 & 6 & 0 & $0.96 \pm 0.03$ & $0.58 \pm 0.02$ & $1.78 \pm 0.05$ \\
\hline 2 & Control & 528 & 153 & 343 & 32 & 0 & 0 & $0.77 \pm 0.02$ & $0.61 \pm 0.02$ & $1.25 \pm 0.02$ \\
\hline 2 & Allatostatin & 400 & 208 & 189 & 3 & 0 & 0 & $0.48 \pm 0.02$ & $0.45 \pm 0.03$ & $1.07 \pm 0.02$ \\
\hline 3 & Control & 498 & 263 & 232 & 3 & 0 & 0 & $0.48 \pm 0.02$ & $0.45 \pm 0.02$ & $1.05 \pm 0.01$ \\
\hline 4 & Allatostatin & 474 & 326 & 148 & 0 & 0 & 0 & $0.32 \pm 0.02$ & $0.31 \pm 0.04$ & $1.00 \pm 0.04$ \\
\hline
\end{tabular}

$m$, mean quantal content of EJCs; $n$, number of putative release sites; $p$, mean probability for release at the recorded site.

significantly reduced in amplitude. This inhibitory effect is never accompanied by changes in the passive electrical properties of the muscle fibres. This is in accord with results obtained on stomach muscles of the crab Cancer borealis (Jorge Rivera \& Marder, 1997). We therefore assume that the signals of the Dip AST ir motor neurons do not convey excitation or inhibition to their target cells, but modulate their responses by altering their properties.

The absence of effects on passive membrane properties suggests that the peptide modulates depolarization activated membrane parameters (e.g. $\mathrm{Ca}^{2+}$ or $\mathrm{K}^{+}$currents) or intrinsic muscle parameters regulating contraction. The possibility of modulation of membrane currents is supported by our findings that, in Idotea, Dip AST 8 inhibits both depolarization accompanied $\mathrm{K}^{+}$contractures of the muscle fibres (T. Weiss, personal communication) and evoked contractions in voltage clamp experiments. However, caffeine contractures generated by $\mathrm{Ca}^{2+}$ release from internal stores without depolarization of the muscle fibre, remain unaffected (T. Weiss, personal communication). We favour the idea that allatostatin depresses the $\mathrm{Ca}^{2+}$ current and/or enhances pre existing voltage dependent $\mathrm{K}^{+}$currents. Voltage clamp analysis will be required for definite answers.

\section{The pre- and postsynaptic effects of allatostatin are complementary}

Our results indicate a twofold inhibitory mechanism of allatostatin. At the presynaptic site, the probability of transmitter release at motor nerve terminals is decreased, resulting in fewer quanta released by an action potential. The consequence is smaller ligand gated currents at the muscle fibre and, thus, smaller EJPs. This will affect the depolarization of the entire fibre upon motor neuron activity and will decrease the resulting contraction. In the presence of allatostatin, a given synaptic input therefore will be less effective. At the postsynaptic site, the reduction of the contraction amplitudes through effects on voltage gated currents will add synergistically to the presynaptic inhibitory effects.

The results with Eriphia show that at least the presynaptic effects of allatostatin are similar for a pair of antagonistic muscles and also for functionally different motor neurons innervating the same muscle fibres. In Idotea, although Dip AST 7 ir motor neurons provide specific innervation to a restricted number of the extensor muscle fibres, the peptide they release modulates all fibres of this muscle. The similar sensitivity of both different muscles and their muscle fibres, whether or not they receive Dip AST 7 ir innervation, and the similar effects on functionally different excitatory motor neurons suggest that allatostatin can cause a rather widespread and general downregulation of excitatory neuromuscular events, regardless of whether they are induced by activity of a slow or a fast motor neuron.

\section{Dual peptidergic modulation of neuromuscular responses}

In the same fibres of the extensor muscles in Idotea in which the inhibitory effect of allatostatin on contractions has been studied (fibre 2 ), the pentapeptide proctolin potentiates the contractions (Erxleben et al., 1995). This is achieved through several synergistic postsynaptic mechanisms. One is the enhancement of the macroscopic inward $\mathrm{Ca}^{2+}$ current entering through dihydropyridine sensitive, voltage depen dent $\mathrm{Ca}^{2+}$ channels (Erxleben \& Rathmayer, 1997; Erxleben \& DeSantis, 1998). A second mechanism involves the closing of a voltage insensitive $\mathrm{K}^{+}$channel (Erxleben etal., 1995). The conse quence of the latter effect is an increase in input resistance resulting in an increase in membrane time constant which prolongs the decay of EJPs and thus facilitates their summation. A given synaptic input will therefore achieve a larger depolarization of the fibres in the presence of proctolin, thus producing an effect opposite to that of allatostatin. The presence of proctolin immunoreactive axons with numerous varicosities on the long fibres 5 and 6 of the extensor muscles of Idotea has indeed been observed (S. Kreissl, personal communication).

Antagonistic peptidergic regulation of muscle contraction has previously been demonstrated for the radula closer and opener, and for buccal muscles in Aplysia (Brezina et al., 1994a,b; Scott et al., 1997; review in Kupfermann, 1998). The present work with Idotea suggests another possibility for dual peptidergic excitatory and inhibitory modulation of muscle performance; in vivo, the synaptic efficiency of motor activation could be up or downregulated, depending on the type and combination of modulators released.

\section{Acknowledgements}

We thank Dr H. J. Agricola (Jena), for the generous gift of the allatostatin antibody, and Professor A. DeSantis (Napoli) and Dr H. D. Franke (Helgoland), for help in obtaining animals. Thanks are due to Mary A. Cahill, Renate Eberle, Marion Häberle, Birgit Rapp and Michael Schmäh, for assistance at various stages of the work, and to Mary A. Cahill for help with the English. This work was supported by grants of the Deutsche Forschungsgemeinschaft (SFB 156, B 5 and Ra 113/8 1), the Fonds der Chemischen Industrie and the Volkswagen Stiftung (I/72 539) to W. R.

\section{Abbreviations}

AST ir, Allatostatin immunoreactive (neurons); Dip AST 7, Allatostatin 1; Dip AST 8, Allatostatin 3; EC, excitation contraction; EJC, excitatory 
junctional current; EJP, excitatory junctional potential; FCE, fast (closer) excitor; mEJC, miniature EJC; OE, opener excitor; $m$, mean quantal content of EJCs; $n$, number of putative release sites; $p$, mean probability for release at the recorded site; peg 1, ganglion 1 in the the pereion; plg 1, ganglion 1 in the the pleon; SCE, slow (closer) excitor.

\section{References}

Abel, B., Dircksen, H. \& Agricola, H. (1994) Allatostatin immunreaktive Neuronensysteme im zentralen und peripheren Nervensystem von Crustaceen. Verh. Dtsch. Zool. Ges., 87, 3.

Bellés, X., Maestro, J.L., Piulachs, M.D., Johnsen, A.H., Duve, H. \& Thorpe, A. (1994) Allatostatic neuropeptides from the cockroach Blattella germanica (L.) (Dictyoptera, Blattellidae). Identification, immuno localization, and activity. Regul. Pept., 53, 237247.

Brezina, V., Evans, C.G. \& Weiss, K.R. (1994a) Enhancement of Ca current in the accessory radula closer muscle of Aplysia californica by neuromodulators that potentiate its contractions. J. Neurosci., 14, 4393 4411.

Brezina, V., Evans, C.G. \& Weiss, K.R. (1994b) Activation of K current in the accessory radula closer muscle of Aplysia californica by neuromodulators that depress its contractions. J. Neurosci., 14, 44124432.

Christie, A.E., Skiebe, P. \& Marder, E. (1995) Matrix of neuromodulators in neurosecretory structures of the crab Cancer borealis. J. Exp. Biol., 198, 24312439.

Cooper, R.L., Stewart, B.A., Wojtowicz, J.M., Wang, S. \& Atwood, H.L. (1995) Quantal measurement and analysis methods compared for crayfish and Drosophila neuromuscular junctions, and rat hippocampus. J. Neurosci. Meth., 61, 6778.

Davis, N.T., Veenstra, J.A., Feyereisen, R. \& Hildebrand, J.G. (1997) Allatostatin like immunoreactive neurons of the tobacco hornworm, Manduca sexta, and isolation and identification of a new neuropeptide related to cockroach allatostatins. J. Comp. Neurol., 385, 265284.

Ding, Q., Donly, B.C., Tobe, S. \& Bendena, W.G. (1995) Comparison of allatostatin neuropeptide precursors in the distantly related cockroaches Periplaneta americana and Diploptera punctata. Eur. J. Biochem., 234, 737746.

Donly, B.C., Ding, Q., Tobe, S.S. \& Bendena, W.G. (1993) Molecular cloning of the gene for the allatostatin family of neuropeptides from the cockroach Diploptera punctata. Proc. Natl Acad. Sci. USA, 90, 88078811.

Dudel, J. (1981) The effect of reduced calcium on quantal unit current and release at the crayfish neuromuscular junction. Pfiügers Arch., 391, 3540.

Dudel, J. (1989) Calcium dependence of quantal release triggered by graded depolarization pulses to nerve terminals in crayfish and frog muscle. Pflügers Arch., 415, 289298.

Duve, H., Johnsen, A.H., Maestro, J.L., Scott, A.G., Crook, N., Winstanley, D. \& Thorpe, A. (1997b) Identification, tissue localisation and physiological effect in vitro of a neuroendocrine peptide identical to a dipteran Leu callatostatin in the codling moth Cydia pomonella (Tortricidae: Lepidoptera). Cell Tissue Res., 289, 7383.

Duve, H., Johnsen, A.H., Maestro, J. L., Scott, A.G., East, P.D. \& Thorpe, A. (1996) Identification of the dipteran Leucallatostatin peptide family: The pattern of precursor processing revealed by isolation studies in Calliphora vomitoria. Regul. Peptides, 67, 1119.

Duve, H., Johnsen, A.H., Maestro, J.L., Scott, A.G., Jaros, P.P. \& Thorpe, A. $(1997 \mathrm{c})$ Isolation and identification of multiple neuropeptides of the allatostatin superfamily in the shore crab Carcinus maenas. Eur. J. Biochem., 250, 727734 .

Duve, H., Johnsen, A.H., Maestro, J. L., Scott, A.G., Winstanley, D., Davey, M., East, P.D. \& Thorpe, A. (1997a) Lepidopteran peptides of the allatostatin superfamily. Peptides, 18, 13011309.

Duve, H., Johnsen, A.H., Scott, A.G., East, P. \& Thorpe, A. (1994) $\left(\mathrm{Hyp}^{3}\right)$ Met callostatin. J. Biol. Chem., 269, 2105921066.

Duve, H., Johnsen, A.H., Scott, A.G. \& Thorpe, A. (1995) Isolation, identification and functional significance of $\left[\mathrm{Hyp}^{2}\right]$ Met callatostatin and des Gly Pro Met callatostatin, two further post translational modifications of the blowfly neuropeptide Met callatostatin. Regul. Pept., 57, 237245.

Duve, H., Johnsen, A.H., Scott, A.G., Yu, C.G., Yagi, K.J., Tobe, S.S. \& Thorpe, A. (1993) Callatostatins: Neuropeptides from the blowfly Calliphora vomitoria with sequence homology to cockroach allatostatins. Proc. Natl Acad. Sci. USA, 90, 24562460.

Duve, H. \& Thorpe, A. (1994) Distribution and functional significance of Leu callatostatin in the blowfly Calliphora vomitoria. Cell Tissue Res., 276, 367379.

East, P.D., Thorpe, A. \& Duve, H. (1995) Leu callatostatin gene expression in the blowflies Calliphora vomitoria and Lucilia cuprina studied by in situ hybridisation: Comparison with Leu callatostatin confocal laser scanning immunocytochemistry. Cell Tissue Res., 280, 355364.

Erxleben, C. \& DeSantis, A. (1998) Properties of the calcium current in crustacean muscle and modulation by proctolin through activation of second messenger pathway. Proceedings 26. Göttingen Neurobiol. Conference, 605.

Erxleben, C.F.J., DeSantis, A. \& Rathmayer, W. (1995) Effects of proctolin on contractions, membrane resistance, and non voltage dependent sarcolemmal ion channels in crustacean muscle fibers. J. Neurosci., 15, 43564369.

Erxleben, C. \& Rathmayer, W. (1997) A dihydropyridine sensitive voltage dependent calcium channel in the sarcolemmal membrane of crustacean muscle. J. Gen. Physiol., 109, 313326.

Gäde, G., Hoffmann, K.H. \& Spring, J.H. (1997) Hormonal regulation in insects: Facts, gaps, and future directions. Physiol. Rev., 77, 9631032.

Jorge Rivera, J.C. \& Marder, E. (1997) Allatostatin decreases stomatogastric neuromuscular transmission in the crab. J. Exp. Biol., 200, 29372946.

Kobierski, L.A., Beltz, B.S., Trimmer, B.A. \& Kravitz, E.A. (1987) FMRFamide like peptides of Homarus americanus: distribution, immunocytochemical mapping and ultrastructural localization in terminal varicosities. J. Comp. Neurol., 166, 115.

Kreissl, S., Uber, A. \& Rathmayer, W. (1995) Embryonic development of allatostatin like immunoreactivity in neuromuscular systems of Locusta migratoria. Proceedings 23. Göttingen Neurobiol. Conference, 205.

Kupfermann, I. (1998) The role of modulatory systems in optimizing behavior: Studies of feeding in the mollusc Aplysia californica. Zool., 100, 235243.

Lange, A.B., Bendena, W.G. \& Tobe, S.S. (1995) The effect of the thirteen Dip allatostatins on myogenic and induced contractions of the cockroach (Diploptera punctata) hindgut. J. Insect Physiol., 41, 581588.

Lange, A.B., Chan, K.K. \& Stay, B. (1993) Effect of allatostatin and proctolin on antennal pulsatile organ and hindgut muscle in the cochroach, Diploptera punctata. Arch. Insect Biochem. Physiol., 24, 7992.

Lorenz, M.W., Kellner, R. \& Hoffmann, K.H. (1995) Identification of two allatostatins from the cricket, Gryllus bimaculatus de Geer (Ensifera, Gryllidae): additional members of a family of neuropeptides inhibiting juvenile hormone biosynthesis. Regul. Pept., 57, 227236.

Nässel, D.R. (1996) Neuropeptides, amines and amino acids in an elementary insect ganglion: functional and chemical anatomy of the unfused abdominal ganglion. Progr. Neurobiol., 48, 325420.

Okada, J. \& Kuwasawa, K. (1995) Neural mechanisms governing distribution of cardiac output in an isopod crustacean, Bathynomus doederleini: Reflexes controlling the cardioarterial valves. J. Comp. Physiol. [A], 176, 479489.

Pratt, G.E., Farnsworth, D.E., Fok, K.F., Siegel, N.R., McCormack, A.L., Shabanowitz, J., Hunt, D.F. \& Feyereisen, R. (1991) Identity of a second type of allatostatin from cockroach brains: an octadecapeptide amide with tyrosine rich address sequence. Proc. Natl Acad. Sci. USA, 88, 24122416.

Pratt, G.E., Farnsworth, N.R., Siegel, N.R., Fok, K.F. \& Feyereisen, R. (1989) Identification of an allatostatin from adult Diploptera punctata. Biochem. Biophys. Res. Commun., 163, 12431247.

Rathmayer, W. \& Erxleben, C. (1983) Identified muscle fibers in a crab. I. Characteristics of excitatory and inhibitory neuromuscular transmission. $J$. Comp. Physiol., 152, 411429.

Rathmayer, W. \& Maier, L. (1987) Muscle fiber types in crabs: Studies on single identified muscle fibers. Am. Zool., 27, 10671077.

Reichwald, K., Unnithan, G.C., Davis, N.T., Agricola, H. \& Feyereisen, R. (1994) Expression of the allatostatin gene in endocrine cells of the cockroach midgut. Proc. Natl Acad. Sci. USA, 91, 1189411898.

Scott, M.L., Brezina, V. \& Weiss, K.R. (1997) Ion currents and mechanisms of modulation in the radula opener muscles of Aplysia. J. Neurophysiol., 78, 23722387.

Siwicki, K.K., Beltz, B.S., Schwarz, T.L. \& Kravitz, E.A. (1985) Proctolin in the lobster nervous system. Peptides, 6, 393402.

Skiebe, P. (1999) Allatostatin like immunoreactivity in the stomatogastric nervous system and the pericardial organs of the crab Cancer pagurus, the lobster Homarus americanus, and the crayfish Cherax destructor and Procambarus clarkii. J. Comp. Neurol., 403, 85105.

Skiebe, P. \& Schneider, H. (1994) Allatostatin peptides in the crab stomatogastric nervous system: Inhibition of the pyloric motor pattern and distribution of allatostatin like immunoreactivity. J. Exp. Biol., 194, 195208.

Stangier, J., Dircksen, H. \& Keller, R. (1986) Identification and immunochemical localization of proctolin in pericardial organs of the shore crab, Carcinus maenas. Peptides, 7, 6772.

Stay, B., Tobe, S.S. \& Bendena, W.G. (1994) Allatostatins: identification, 
primary structures, functions and distributions. Adv. Insect Physiol., 25, 267337.

Trube, A., Audehm, U. \& Dircksen, H. (1994) Crustacean cardioactive peptide immunoreactive neurons in the ventral nervous system of the crayfish. J. Comp. Neurol., 348, 8093.

Vanden Broeck, J., Veelaert, D., Bendena, W.G., Tobe, S.S. \& DeLoof, A. (1996) Molecular cloning of the precursor cDNA for schistostatins, locust allatostatin like peptides with myoinhibiting properties. Mol. Cell. Endocrinol., 122, 191198.

Veelaert, D., Devreese, B., Schoofs, L., Van Beeumen, J., Vanden Broeck, J., Tobe, S.S. \& DeLoof, A. (1996) Isolation and characterization of eight myoinhibiting peptides from the desert locust Schistocerca gregaria: New members of the cockroach allatostatin family. Mol. Cell. Endocrinol., 122, 183190.

Veenstra, J.A., Noriega, F.G., Graf, R. \& Feyereisen, R. (1997) Identification of three allatostatins and their cDNA from the mosquito Aedes aegypti. Peptides, 18, 937942.

Vitzthum, H., Homberg, U. \& Agricola, H. (1996) Distribution of dip allatostatin I like immunoreactivity in the brain of the locust Schistocerca gregaria with detailed analysis of immunostaining in the central complex. $J$. Comp. Neurol., 369, 419437.

Walker, R. (1935) The central nervous system of Oniscus (Isopoda). J. Comp. Neurol., 62, 197238.
Weaver, R.J., Freeman, Z.A., Pickering, M.G. \& Edwards, J.P. (1994) Identification of two allatostatins from the CNS of the cockroach Periplaneta americana: novel members of a family of neuropeptide inhibitors of insect juvenile hormone biosynthesis. Comp. Biochem. Physiol., 107C, 119127.

Weiss, T. \& Agricola, H. (1996) A new aspect of allatostatin action: modulation of neuro muscular transmission in the cockroach hindgut. Proceedings 24. Göttingen Neurobiol. Conference, 579.

Wiens, T.J., Maier, L. \& Rathmayer, W. (1988) The distribution of the common inhibitory neuron in brachyuran limb musculature. II. Target fibers. J. Comp. Physiol. [A], 163, 651664.

Woodhead, A.P., Khan, M.A., Stay, B. \& Tobe, S.S. (1994) Two new allatostatins from the brain of Diploptera punctata. Insect Biochem. Mol. Biol., 24, 257263.

Woodhead, A.P., Stay, B., Seidel, S.L., Khan, M.A. \& Tobe, S.S. (1989) Primary structure of four allatostatins: neuropeptide inhibitors of juvenile hormone synthesis. Proc. Natl Acad. Sci. USA, 86, 59976001.

Yu, C.G., Stay, B., Joshi, S. \& Tobe, S.S. (1993) Allatostatin content of brain, corpora allata and haemolymph at different developmental stages of the cockroach, Diploptera punctata: quantitation by ELISA and bioassay. $J$. Insect Physiol., 39, 111122.

Zucker, R.S. (1973) Changes in the statistics of transmitter release during facilitation. J. Physiol. (Lond.), 229, 787810. 